CORRECTION

\title{
Correction to: Gemcitabine + Nab-paclitaxel or Gemcitabine alone after FOLFIRINOX failure in patients with metastatic pancreatic adenocarcinoma: a real-world AGEO study
}

Sonia Zaibet, Vincent Hautefeuille, Edouard Auclin, Astrid Lièvre, David Tougeron (D), Mathieu Sarabi, Marine Gilabert, Julie Wasselin, Julien Edeline (D), Pascal Artru, Dominique Bechade, Clémence Morin, Agnes Ducoulombier, Julien Taieb (iD) and Simon Pernot (iD)

(c) The Author(s), under exclusive licence to Springer Nature Limited 2022

British Journal of Cancer (2022) 126:969; https://doi.org/10.1038/s41416-022-01734-5

Correction to: British Journal of Cancer https://doi.org/10.1038/s41416022-01713-w, published online 29 January 2022
In this article the author name Sonia Zaibet was incorrectly written as Simon Zaibet. The original article has been corrected. 